\title{
Utilization of screening services for cancer of the cervix in Makurdi, Nigeria
}

Bernard Terkimbi Utoo ${ }^{1 *}$, Stephen Dungbe Ngwan² and Ajen Stephen Anzaku

*Correspondence: bernardutoo@yahoo.com

'Obstetrics and Gynaecology Department Benue State University Teaching Hospital, Makurdi, Nigeria.

${ }^{2}$ Federal Medical Centre, Makurdi, Nigeria.

${ }^{3}$ Bingham University Teaching Hospital, Jos, Plateau State, Nigeria.

\begin{abstract}
Background: Cancer of the cervix is a leading cause of death due to female genital malignancies in developing countries. Early detection through cervical screening is crucial for prevention and treatment.

Objective: To determine the awareness and utilization of screening services for cancer of the cervix amongst women in Makurdi.

Methods: A cross-sectional study using interviewer administered questionnaires to women attending the outpatient gynecological clinic at the Benue State University Teaching Hospital, Makurdi, North-Central, Nigeria between March and August 2012.

$\underline{\text { Results: }}$ The average age and parity of respondents was $35 \pm 11.2$ years and $2.4 \pm 2.3$ respectively. Most $48.3 \%$ were civil servants, Married $89.0 \%$ and had post-secondary education (64.5\%). About 65\% were aware of cancer of the cervix. Fifty one percent were aware of cervical cancer screening. Main source of information was through the mass media (35.5\%). Among the 'aware' group for screening services, only $13.6 \%$ had utilized the services $\left(\mathrm{X}^{2}=12.2, \mathrm{p}=0.0004, \mathrm{OR}=3.7\right)$. Overall, only $7 \%$ of the study population have ever screened for the disease. Education significantly affected awareness for both cancer of the cervix $(p=0.0001)$ and screening services $(\mathrm{P}=0.0002)$. Reasons for non utilization of services were; Ignorance, absence of screening centres, perceived non necessity, faith in God, prohibitive cost, physician's non recommendation among others.

Conclusion: Most women were aware of cancer of the cervix and screening for the disease but utilization of screening services was very poor. Services should be made available, accessible and affordable to the women while sustaining awareness campaigns.

Keywords: Cervical cancer, screening services, awareness, utilization, pap smear
\end{abstract}

\section{Introduction}

Cervical cancer is the second commonest malignancy affecting women worldwide [1,2]. It is the leading genital tract malignancy in developing nations. It is also the leading cause of cancer deaths among women in developing countries [1]. Out of the half a million women affected annually worldwide. Nearly 250, 000 deaths are reported every year [2]. Eighty percent of these women do not only come from countries that control only $20 \%$ of the world's cancer resources, they also present for treatment very late in which case only palliative measures can be offered to them $[3,4]$.

This genital tract malignancy is for now the only reproductive tract cancer that can be detected at an early stage before it becomes frankly invasive. The use of the papanicolaou smear (named after the Greek physician) for screening the pre-invasive phase has demonstrated to be helpful in early detection and cure of the cancer $[3,5]$. The fact that the organ in question is easily accessible and the symptoms of the disease could manifest early makes quick diagnosis and cure possible.

Considering the public health significance and the magnitude of the disease several communities especially in the developed nations of the world adopted mass screening measures so as to prevent as well as reduce the burden of cervical cancer [4].
Some developed countries had even made it a law through their parliament making screening the right of women to live. The story is not the same in most developing countries where awareness is poor and several barriers against utilization of screening services exist.

In Nigeria, like other developing nations, awareness and utilization of screening services is not encouraging [5]. Even the opportunistic screening attitude of health workers in Nigeria is not widely practice by most reproductive health experts. Surprisingly, studies have shown that despite their knowledge of the disease and that of the importance of screening amongst female health workers, utilization of services is poor [6].

Various barriers have been reported to be responsible for non utilization of screening services in some parts of the country. This study was designed to assess the awareness, utilization of screening services and barriers to utilization of screening services for cancer of the cervix in Makurdi, North-Central, Nigeria.

\section{Methodology}

This was a cross-sectional study using interviewer administered questionnaires to 172 respondents. The study population were patients attending the out-patient gynaecological clinic at the 
Utoo et al. Journal of Reproductive Biology and Health 2013,

Table 1. Distribution of awareness of cervical cancer and screening.

\begin{tabular}{lll}
\hline Awareness of CA cervix & Frequency & Percentage \\
\hline No & 60 & $34.9 \%$ \\
Yes & 112 & $65.1 \%$ \\
Total & 172 & $100.0 \%$ \\
\hline Awareness of screening & & \\
\hline No & 84 & $48.8 \%$ \\
Yes & 88 & $51.2 \%$ \\
Total & 172 & $100.0 \%$ \\
\hline
\end{tabular}

Table 2. Relationship between awareness of screening, marital status and utilization of services.

\begin{tabular}{lllll}
\hline \multicolumn{5}{l}{ Utilization of services } \\
\hline $\begin{array}{l}\text { Awareness of } \\
\text { screening }\end{array}$ & NO & YES & Total & Statistics \\
\hline No & $84(100)$ & $0(0)$ & $84(100)$ & $\mathrm{X}^{2}=12.2$ \\
Yes & $76(86.4)$ & $12(13.6)$ & $88(100)$ & $\mathrm{P}=0.0004$ \\
Total & $160(93.0)$ & $12(7.0)$ & $172(100)$ & $\mathrm{OR}=3.7$ \\
\hline Marital Status & & & & \\
\hline Married & $143(93.5)$ & $10(6.5)$ & $153(100)$ & $\mathrm{X}^{2}=0.03$ \\
Single & $17(89.5)$ & $2(10.5)$ & $19(100)$ & $\mathrm{P}=0.62$ \\
Total & $160(93.0)$ & $12(7.0)$ & $172(100)$ & -- \\
\hline
\end{tabular}

Table 3. Reasons for non utilization of services.

\begin{tabular}{lcc}
\hline Reasons & Frequency (N) & Percentage (\%) \\
\hline Ignorance & 76 & 47.5 \\
Absence of screening centers & 27 & 16.9 \\
Perceived non necessity & 14 & 8.8 \\
Faith in God & 12 & 7.5 \\
Cost & 7 & 4.3 \\
Physician's non recommendation & 6 & 3.7 \\
Others & 18 & 11.3 \\
Total & 160 & 100.0 \\
\hline
\end{tabular}

Others: Not having symptoms, lack of opportunity, No reason.

Benue State University Teaching Hospital Makurdi (BSUTH), between March and August 2012. The gynaecology clinic holds thrice a week with an average of twenty five patients per day.

The hospital is one of the two tertiary health facilities in the state and the only state University Teaching hospital north of the Niger. It is a new facility that is barely a year and a half old. It is located in Makurdi town the state capital. Makurdi Local Government Area (LGA) constitutes one of the 23 LGAs in the state [7]. Benue state which has an area of about $34,059 \mathrm{~km}$ [2] is located in the north-central part of Nigeria. It is bounded to the North by Nassarawa state, by Taraba state to the east,
Ebonyi/Cross-rivers states to the south and Kogi state to the west. It has about 5 million people who are mainly farmers, civil servants and traders [7].

Data collection was done by the nurses at the clinic. Questionnaires were administered to all participants who consented to be part of the research. The questionnaire had two parts. Section A: This focused on socio demographic characteristics of the women. These were; Initials, age, occupation, level of education, ethnicity, marital status, parity and religion. Section B: This focused on awareness of cervical cancer, source of information, prevention of cancer of the cervix, whether the respondents have seen someone with cancer of the cervix, whether there is cure or not for the disease, awareness of screening for the disease, utilization of screening services, the frequency of screening and reasons for non-utilization of services. It took approximately 15 minutes to complete the questionnaire. The Data was analysed using EPI INFO statistical software version 3.2.2. Data is presented in simple tables. Chi-square was used as a test of statistics with $p$-value $\leq 0.05$ considered statistically significant.

\section{Results}

A total of 172 respondents were studied. Their average age and parity were $35 \pm 11.2$ years and $2.4 \pm 2.3$ respectively. Most $48.3 \%$ were civil servants, Married $89.0 \%$ and had post-secondary education (64.5\%). About $65 \%$ were aware of cancer of the cervix. Fifty one percent were aware of cervical cancer screening (Table 1). The Main source of information was through the mass media (35.5\%). Among the 'aware' group for screening services, only $13.6 \%$ had utilized the services $\left(X^{2}=12.2, p=0.0004, O R=3.7\right)$. Overall, only $7 \%$ of the study population have ever screened for the disease (Table 2). Education significantly predicted awareness for both cancer of the cervix $(p=0.0001)$ and screening services $(P=0.0002)$. However, utilization of screening services was not significantly influenced by education, parity, occupation and marital status. Respondents gave reasons for non utilization of services to include; Ignorance, absence of screening centres, perceived non necessity, faith in God, prohibitive cost and physician's non recommendation among other reasons (Table 3).

\section{Discussion}

The average age and parity of the women is a reflection of the common group affected by the disease. The disease is said to have two peaks which are 35 and 55 years of age. It is not common among teenagers although young women in their twenties have been reported to have advanced stage disease [1]. There is need to intensify efforts towards promoting awareness and screening for premalignant lesions of the cervix among these category of women.

Interestingly, single women were more likely to screen than the married women although the difference was not statistically significant. This is encouraging and the determination should be sustained bearing in mind that 
early sexual activity as well as multiple sexual partners are risk factors for cancer of the cervix [2]. More so studies have shown a declining age at coitache.

One-third of the respondents were aware of cervical cancer and half were aware of screening for premalignant lesions of the cervix. This is in contrast to the findings in other studies done in the eastern part of the country where awareness was low $[4,5]$. This finding was however similar to the report of a study done among female health workers in Abuja, Nigeria [6]. The report of high awareness is due to the high level of education among the women. Education was significantly related to awareness for both the disease and screening services. A similar finding was reported by Nwankwo et al., in eastern Nigeria [8]. Emphasis on girl child education should therefore be sustained.

Sustaining the use of mass media in disseminating information to the general populace is imperative. Most of our respondents got their information from this source. Thus, media houses should endeavour to promote health education through campaigns, dramas, debates and advertisement either free of charge or at subsidized rates. The over commercialization of the mass media should be revisited especially when it has to do with issues of reproductive health.

Similar to findings of other studies, this study reports low utilization of screening services among the "aware" group for cervical cancer screening $(13.6 \%)[3,6]$. As low as $7 \%$ of the entire population studied had ever screened for the disease. Although, this rate is higher than the $2.6 \%$ and $4.2 \%$ in western and eastern Nigeria respectively $[\mathbf{8 , 9}]$. The rate is however lower than the finding reported by Dim et al., eastern Nigeria and Hoque et al., in a rural community in South Africa [10]. This should raise a serious level of concern for all stake holders in reproductive health. The parliament should be magnanimous to make laws that will promote screening as has been done in other parts of the world.

The study finds several reasons for non utilization of services. These include; Ignorance, absence of screening centres, perceived non necessity, faith in God, prohibitive cost and physician's non recommendation. Some of these obstacles to screening were reported by other authors [3]. What is needed is re-strategizing on how best information on cancer of the cervix can be effectively disseminated.

Health workers should help change the perception of non susceptibility of women. They should be made to understand that as long as a woman is sexually active she stands a chance of been affected. More screening centres should be designated. So, a well organized national mass screening programme is much desirable and long overdue. Screening should be free or at a highly subsidized cost.

Training and retraining of health workers to provide services is important. Health workers should recommend at least a yearly cervical screening for women. Social mobilization efforts must target community leaders, traditional rulers, religious organizations and faith based institutions and not just families. Nongovernmental organizations can partner with health institutions in promoting service availability, affordability and utilization.

\section{Conclusion}

Most women were aware of cancer of the cervix and screening for the disease but utilization of screening services was very poor. Emphasis should be made towards the provision, accessibility and affordability of cervical screening services to the women while sustaining awareness campaigns.

\section{Competing interests}

The authors declare that they have no competing interests.

\section{Authors' contributions}

\begin{tabular}{|l|c|c|c|}
\hline Authors' contributions & BTU & SDN & ASA \\
\hline Research concept and design & $\checkmark$ & $\checkmark$ & $\checkmark$ \\
\hline Collection and/or assembly of data & $\checkmark$ & -- & -- \\
\hline Data analysis and interpretation & -- & $\checkmark$ & -- \\
\hline Writing the article & $\checkmark$ & -- & $\checkmark$ \\
\hline Critical revision of the article & $\checkmark$ & -- & $\checkmark$ \\
\hline Final approval of article & $\checkmark$ & $\checkmark$ & $\checkmark$ \\
\hline Statistical analysis & -- & $\checkmark$ & -- \\
\hline
\end{tabular}

Acknowledgement

Many thanks to the Nursing staff who work in the Gynaecology clinic of the hospital for diligent data collection.

Publication history

Editor: Eddie Fernando Candido Murta, Federal University of Triangulo Mineiro, Brazil.

EIC: Zeev Blumenfeld, Technion - Israel Institute of Technology, Israel. Received: 25-Oct-2013 Revised: 06-Nov-2013

Accepted: 08-Nov-2013 Published: 02-11-2013

\section{References}

1. Kikelomo A, Rakiya S, Abiodun A, Adegboyega F, Adebunmi O and Kazeem I. Factors contributing to low uptake of cervical screening in a population at risk. Trop J Obstet Gynaecol. 2009; 26:35-41. I Article

2. Balogun M R, Odukoya OO, Oyediran M A and Ujomu P I. Knowledge of cervical cancer and its risk factors among women residing in two urban slums in Lagos, Nigeria. Nig Med Pract. 2012; 61:74-81. | Article

3. Aboyeji P A, ljaiya MA and Jimoh AG. Knowledge, Attitude and practice of cervical smear as a screening procedure for cervical cancer in Ilorin, Nigeria. Trop J Obstet Gynaecol. 2004; 21:114-7. | Article

4. Feyi-Waboso PA, Kamanu $C$ and Aluka C. Awareness and Risk factors for cervical cancer among women in Aba,South-Eastern, Nigeria. Trop J Obstet Gynaecol. 2005; 22:25-28. I Article

5. Chukwuali LI, Onuigbo WIB and Mgbor NC. Cervical cancer screening in Enugu,Nigeria. Trop J Obstet Gynaecol. 2003; 20:109-12. | Article

6. Olaniyan $\mathrm{OB}, \mathrm{Agboghoroma} \mathrm{OC}$ and Ladipo OP. Knowledge and practice of cervical screening amongst female health workers in government hospitals in Abuja Metropolis, Nigeria. Trop J Obstet Gynaecol. 2000; 17:18-20.

7. Utoo PM, Utoo BT and Nwokedi EOP. Human Immunodeficiency Virus Status of pregnant women accessing care at a Primary Healthcare Centre in Makurdi North-Central, Nigeria. J Med Trop. 2013; 15:20-23. | Article

8. Nwankwo KC, Aniebue UU, Aguwa EN, Anarado AN and Agunwah 
Utoo et al. Journal of Reproductive Biology and Health 2013,

http://www.hoajonline.com/journals/pdf/2054-0841-1-2.pdf

E. Knowledge attitudes and practices of cervical cancer screening among urban and rural Nigerian women: a call for education and mass screening. Eur J Cancer Care (Engl). 2011; 20:362-7. | Article | PubMed

9. Oladepo $O$, Ricketts $\mathrm{OL}$ and John-Akinola Y. Knowledge and utilization of cervical cancer screening services among Nigerian students. Int $Q$ Community Health Educ. 2008; 29:293-304. | Article | PubMed

10. Dim CC, Nwagha UI, Ezegwui HU and Dim NR. The need to incorporate routine cervical cancer counselling and screening in the management of women at the outpatient clinics in Nigeria. J Obstet Gynaecol. 2009; 29:754-6. | Article | PubMed

\section{Citation}

Utoo BT, Ngwan SD and Anzaku AS. Utilization of creening services for cancer of the cervix in Makurdi, Nigeria. J Reprod Biol Health. 2013; 1:2.

http://dx.doi.org/10.7243/2054-0841-1-2 